\title{
Mitochondrial Adaptations in Aged Skeletal Muscle: Effect of Exercise Training
}

\author{
M. M. ZIAALDINI ${ }^{1}$, S. R. A. HOSSEINI ${ }^{1}$, M. FATHI ${ }^{1}$ \\ ${ }^{1}$ Faculty of Sport Science, Ferdowsi University of Mashhad, Mashhad, Iran
}

Received February 23, 2016

Accepted July 1, 2016

On-line December 16, 2016

\section{Summary}

The aging process is associated with a decline in mitochondrial functions. Mitochondria dysfunction is involved in initiation and progression of many health problems including neuromuscular, metabolic and cardiovascular diseases. It is well known that endurance exercise improves mitochondrial function, especially in the elderly. However, recent studies have demonstrated that resistance training lead also to substantial increases in mitochondrial function in skeletal muscle. A comprehensive understanding of the cellular mechanisms involved in the skeletal muscle mitochondrial adaptations to exercise training in healthy elderly subjects, can help practitioners to design and prescribe more effective exercise trainings.
\end{abstract}

\section{Key words}

Mitochondrial dysfunction • Aging • Exercise training

\section{Corresponding author}

M. M. Ziaaldini, Faculty of Sport Sciences, Ferdowsi University of Mashhad, Azadi Square, Mashhad, Iran. E-mail: mosaferi@um.ac.ir

\section{Introduction}

Aging is an intricate phenomenon characterized by progressive decline in physiological functions and increase in mortality that is often accompanied by many pathological diseases (Cui et al. 2012). Mitochondrial dysfunction is heavily implicated in the ageing process (Trifunovic and Larsson 2008). Many studies have demonstrated that a disruption of mitochondrial integrity leads to the initiation and progression of many health problems including neuromuscular (Jones et al. 2003, Wallace 1989), metabolic (Lowell and Shulman 2005, Saxena et al. 2006) and cardiovascular diseases (Hall et al. 2014, Mercer 2014). Mitochondria are intracellular organelles whose main duty is to provide cellular energy requirements (Verdin et al. 2010). Mitochondrion contain a double membrane layer and hundreds of protein and 2-10 copies of mitochondrial DNA (mtDNA) are surrounded in matrix by the mitochondrial inner layer (Lee and Wei 2005). Although the mitochondrion has its own genome, it codes just 13 mitochondrial proteins, hence mitochondrial biogenesis arises from a coordinated regulation of nuclear and mitochondrial genes (Goffart and Wiesner 2003). In addition to ATP synthesis, mitochondria are involved in pyrimidines and hemes biosynthesis (Atamna 2004, Sherman 2008), apoptosis (Estaquier et al. 2012, Wang and Youle 2009) as well as transcription, translation and replication of mtDNA (Clayton 2000). Mitochondrial network is also a major source of reactive oxygen species (ROS) (Murphy 2009). Reduced mitochondrial function as a result of aging in skeletal muscle (Hebert et al. 2010, Picard et al. 2011, Sahin and Depinho 2010) could support the claim that mitochondria play a critical role in the survival of the cells.

It is well recognized that acute and chronic of endurance training (ET) (Holloszy and Coyle 1984, Holloszy et al. 1970, Willis and Jackman 1994, Wright et al. 2007b) and resistance training (RT) (Shepherd et al. 2014, Wang et al. 2011) have effects on mitochondrial function in young and adults subjects. 
Despite a large body of literature on many aspects of the role of exercise training and mitochondria on different tissues such as heart, kidney and liver and also age related pathologic condition and diseases such as neuromuscular (Abresch et al. 2012, Nardin and Johns 2001), metabolic (Newman et al. 2012, Tjonna et al. 2008) and cardiovascular (Jenkins et al. 2012, Lesnefsky et al. 2001) disease, little is known about the impact of exercise training on skeletal muscle mitochondrial (SM-mito) adaptations in healthy aged mammalian cells.

In this article, first we will have a short overview on mitochondrial function. Then mitochondrial changes in healthy aged subjects will be discussed and finally we will review studies in relation with the effect of exercise training on SM-mito in the elderly. This review solely concerns studies that have investigated the influence of exercise training on SM-mito responses in healthy elderly subjects including humans and animals.

\section{A brief overview of mitochondria function}

Mechanism controlling mitochondria dynamic

Mitochondrial function is dependent on a number of factors including mitochondrial biogenesis and mitochondrial dynamics (Shabrokh et al. 2014). Mitochondria are highly dynamic organelles (Westermann 2012) and are recognized as important constituents of cellular quality control (Westermann 2010). This dynamic behavior of mitochondria includes mitochondrial fission and fusion: the two events controlling mitochondrial shape, size, and number (Scott and Logan 2011). Fusion involves the mixing of mitochondrial material, whereas fission divides the organelle into smaller components (Iqbal and Hood 2014). In mammalian cells, three large GTPases are important for mitochondrial fusion, which requires the coordinated fusion of the outer and inner membranes. The mitofusins, Mfn1 and Mfn2, are located on the mitochondrial outer membrane and are involved in early steps in membrane fusion. The dynamin-related protein OPA1 is associated with the inner membrane and is essential for inner membrane fusion (Chen et al. 2010). The opposing process of mitochondrial fission depends on the dynamin-related protein Drp1 (Chan 2006). The fusion process requires three steps: docking, mitochondria outer membrane (MOM) fusion and mitochondria inner membrane (MIM) fusion. Mfn1 and Mfn2 are thought to play an important role in docking and MOM fusion. Optic atrophy 1 (Opa1) seems to be involved in the formation of cristae junctions as well as in MIM fusion, which occurs in a GTP-dependent manner. Mitochondrial fission 1 (Fis1) is a MOM protein and is thought to recruit Drp1 to the MOM by means of adaptor proteins (Seo et al. 2010). Upon stimulation, Drp1 is activated and translocates to the scission sites of OMM through interaction with Fis1, where they oligomerize and form spirals to constrict OMM through GTP hydrolysis, resulting in mitochondrial fission (Zhan et al. 2013) (Fig. 1A).

\section{Mechanism controlling mitochondria biogenesis}

Mitochondrial biogenesis is a key physiological process that is required for normal growth and development and for maintenance of ongoing cellular energy requirements during aging (Stefano et al. 2012). Mitochondrial biogenesis is now recognized as a vital and exciting area of cell biology and can be defined as the growth and division of pre-existing mitochondria (Jornayvaz and Shulman 2010, Joseph et al. 2006). Mitochondrial biogenesis is a highly regulated process that requires a close coordination between both nuclear and mitochondrial gene expression and recruitment or import of new mitochondrial proteins into preexisting mitochondrial compartments (Sharma et al. 2014, Wright et al. 2008). Controlling the biogenesis of mitochondria and the maintenance of mtDNA is a complex biological process.(Lee and Wei 2005). It involves changes in the expression of more than 1,000 genes, the cooperation of two genomes, and alters the level of approximately $20 \%$ of cellular proteins (Lopez-Lluch et al. 2008). At the molecular level, several transcription factors and cofactors are involved in the activation and regulation of mitochondrial biogenesis (Lopez-Lluch et al. 2008). Expression of genes promoting mitochondrial biogenesis is predominantly controlled by the global principles of gene regulation, that is, transcription initiation and interaction at the gene promoter Therefore, transcription factors and transcriptional coactivators represent critical regulators of mitochondrial biogenesis (Hawley 2009). Transcription factors involved in this process are mitochondrial transcription factor A (TFAM), nuclear respiratory factors (Nrf1, Nrf2), cyclic AMP-activated protein kinase (AMPK), peroxisome proliferatoractivated receptors (PPARs) and peroxisome proliferatoractivated receptor gamma coactivator 1-alpha (PGC-1 $\alpha$ ) (Bori et al. 2012) (Fig. 1B). 


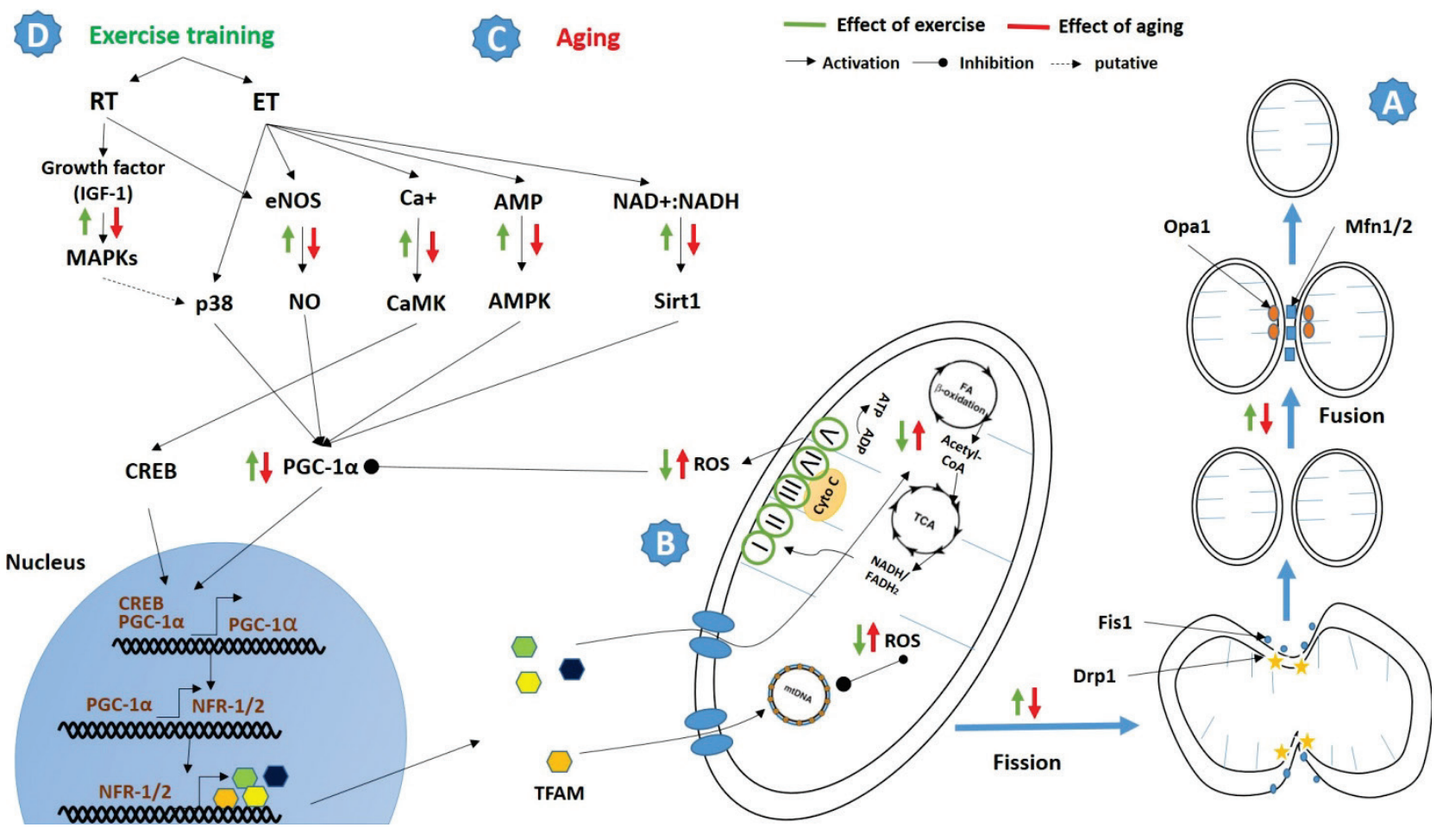

Fig. 1. Diagrammatic summary of the interaction between aging and exercise training and its effect on mitochondria function in healthy mammalian skeletal muscle cell. (A) Fission and fusion. Fis1 is localized uniformly to the mitochondrial outer membrane, whereas Drp1 is localized to the cytosol and associates with Fis1, forming an oligomeric ring-like structure leading to separation of the mitochondria. Fusion is regulated by Mfn1 and Mfn2 isoforms in the outer mitochondrial membrane and by OPA1 protein in the inner mitochondrial membrane. (B) Mitochondria biogenesis. PGC-1a is known as a master regulator of mitochondria biogenesis which its gene expression is mediated by other factors such as AMPK, Sirt1, CaMk, NO and p38. PGC-1a gene expression along with the expression of NRF-1 and NRF-2 induce the expression of TFAM, which is imported into mitochondria. TFAM regulates the expression of the mtDNA gene products, including proteins such as cytochrome c oxidase subunit I (COX I) and also is involved in ATP synthesis. (C) Aging reduced mitochondria function by several ways. Increasing ROS accumulation in cytosol due to an increased 0-2 leaking from ETC decreases PGC-1a activity. Also, increased ROS level inside mitochondria leads to mtDNA mutation and consequently negative effects on mitochondria dynamic and efficiency. Aging is also along with a decrease in PGC-1a upstream signaling pathways such as the levels of eNOS, Ca+, AMP:ATP and NAD+:NADH as well as decreased growth factor levels like IGF-1. (D) Both types of ET and RT exerciseinduced initiation and propagation of mitochondrial biogenesis in muscle. Intracellular levels of Ca2+, CAMP, NO, and the ATP/AMP ratio are modulated by exercise and induced up-regulation of PGC-1 expression. PGC-1 also seems to regulate its own transcription. Increased expression and activity of PGC-1a stimulate mitochondrial biogenesis by activating relevant transcription factors (e.g. NRF-1, NRF-2, and TFAM) resulting in an increase in mitochondrial volume and biogenesis. RT can also positively regulate mitochondria biogenesis. One potential mechanism can be due to the activation of IGF-1/MAPK pathway following RT.

\section{Signals controlling mitochondrial biogenesis: central role of PGC-1a}

Despite the complexity of the various signaling pathways that converge to regulate mitochondrial biogenesis, they all seem to share the common key component of the PGC-1 family of co-transcription factors (Lopez-Lluch et al. 2008). PGC-1 $\alpha$ is preferentially expressed in muscles enriched in slowtwitch type I fibers and drives the formation of slowtwitch fibers (Li et al. 2011). Overexpression of PGC-1 $\alpha$ in the mouse skeletal muscle and heart has been shown to increase mitochondrial biogenesis and function (Dillon et al. 2012). There is growing evidence to suggest that PGC-1 $\alpha$ is a major regulator of mitochondrial biogenesis (Davinelli et al. 2013, Dillon et al. 2012, Lee and Wei
2005) (Fig. 1B).

\section{PGC-1 $\alpha$ downstream signaling pathways}

Most relevant to the onset of mitochondrial biogenesis is the interaction of PGC-1 $\alpha$ with the nuclear respiratory factors NRF-1 and NRF-2 (Hood 2009). Furthermore, NRF-1 is implicated in the interaction with several mitochondrial genes including the TFAM, one of the most important mammalian transcription factors for mtDNA (Davinelli et al. 2013) that directly stimulates mtDNA replication and transcription (Kang et al. 2013). TFAM binds to mtDNA at both the heavy- and lightstrand promoters to initiate the transcription of genes. It also leads to an increase in mtDNA copy number (Huang and Hood 2009) (Fig. 1B). 


\section{PGC-1 up-stream signaling pathways}

Multiple endogenous and exogenous factors regulate mitochondrial biogenesis through the PGC-1 $\alpha$ (Lopez-Lluch et al. 2008). PGC-1 $\alpha$ expression and activity are largely regulated by upstream signaling pathways of protein kinases (Yan et al. 2012) such as p38 mitogen-activated protein kinase (p38 MAPK) (Hood 2009, Joseph et al. 2006, Kang et al. 2013, Li et al. 2011), AMPK (Jager et al. 2007, Reznick et al. 2007, Zong et al. 2002). Moreover, it was demonstrated that changes in intracellular $\mathrm{Ca}^{2+}$ concentrations stimulate calcium/calmodulin-dependent protein kinase IV (CaMK). Thus, CaMK overexpression appeared to induce a coordination of the nuclear and the mitochondrial genomes through PGC-1 $\alpha$ (Joseph et al. 2006, Lee and Wei 2005, Lopez-Lluch et al. 2008).

PGC- $1 \alpha$ is also regulated by post-translational modification, such as phosphorylation and deacetylation. The NAD-dependent deacetylase silent mating type information regulation 2 homolog-1 (Sirt1) is also purported to have a key role in mitochondrial biogenesis via functional regulation of PGC-1 $\alpha$ (Palmer 2010, Yan et al. 2012). Recently, nitric oxide (NO) was shown to regulate mitochondrial biogenesis through the transcriptional activation of PGC-1 $\alpha$ (Lopez-Lluch et al. 2008). In addition, targeted disruption of the endothelial nitric oxide synthase (eNOS) gene in vivo resulted in significant reduction in the level of mitochondrial mass (Lee and Wei 2005, Nisoli et al. 2003) (Fig. 1B).

\section{Ageing-induced SM-mito dysfunction}

Mitochondrial net has an essential role in energy production (Bori et al. 2012) and an impaired in mitochondrial health, including reducing the size and content associated with decreased muscle mass and mtDNA mutation (Konopka et al. 2014, Menshikova et al. 2006). Studies on humans and animals have shown that aging leads to a decrease in the several complexes of electron transport chain I, II, III and IV $28 \%-42 \%$ (Hood 2009, Kumaran et al. 2004), a decrease in oxidative phosphorylation capacity in muscle (Coggan et al. 1992a, Cooper et al. 1992), low mitochondria enzyme activity such as citrate synthase (CS), succinate dehydrogenase (SDH) and Beta-hydroxyacylcoA dehydrogenase (B-HAB) (Melov et al. 2007), decreased mtDNA content (Short et al. 2005) and increased oxidative stress (Huang and Hood 2009, Parise et al. 2005). Electron microscopy analysis showed a reduction in the volume and density (66\% and $25 \%$ respectively) of mitochondria in skeletal muscle in older adults compared to young (Huang and Hood 2009). Also significant decrease observed in muscle protein content of Cytochrome $\mathrm{C}$ and Cox 4 of old rats compared to young ones which was an indicating of decreased mitochondria content (Ziaaldini et al. 2015). It has also shown that the mitochondria in aging muscles are abnormally rounded (Terman et al. 2010). Specific mechanisms leading to the changes of aging are unclear now (Menshikova et al. 2006). Studies on human and animal models have shown that mitochondrial dysfunction is associated with excessive production of ROS and metabolic changes (Bori et al. 2012, Ziaaldini et al. 2015). Mitochondrial theory of aging, which was first introduced in 1979 by Herman Denham suggest that leakage of free radicals and attack neighboring mtDNA leading to mitochondrial mutations that undermine mitochondrial function (Cobley et al. 2013, Nisoli and Carruba 2006). In fact, mtDNA has no protective histones and has substantially less repair mechanisms than nuclear DNA. Thus, ROS-induced accumulations in faulty proteins, oxidized fatty acids, and mtDNA mutations would result in a progressive, feed-forward, and irreversible cycle of cellular dysfunction that leads to the onset of phenotypes associated with aging (Huang and Hood 2009). Functional and dynamic changes of mitochondria associated with aging may contribute to mitochondrial dysfunction. Mitofusion (MFN1, MFN2) and mitofission (Fis1, Drp1) proteins act as morphological mechanisms and remove the mutant and damaged proteins out of mitochondrial for disintegration and contribute to new organelles synthesis (Lee and Wei 2005). However, the impact of aging on these genes is still poorly understood. Konopka et al. reported that there was no difference in levels of MFN1, MFN2 and Fis1 between old (74 \pm 3 years) and young men ( $20 \pm 1$ years) (Konopka et al. 2014). Joseph et al. (2012) achieved similar results where there was no significant difference in levels of MFN2, Drp1 and Fis1 but an increase in OPA1 among older ( $81 \pm 1$ years) rather than young ( $23 \pm 1$ years) men and women. In line with the previous research, Bori et al. (2012) reported which significant differences were not observed in the mRNA levels of young and old sedentary individuals for Fis1, Mfn1. However, animal model studies have shown an age-related increase in protein levels of Drp1 and Fis1 (Bo et al. 2013, Lanza and Nair 2009) and a decrease in levels of MFN1 (Estaquier et al. 2012). Among the many factors that affect the aging 
process, malnutrition and decreased mitochondrial biogenesis appear to be of potential contribution to aging. The exact cause of decreased mitochondrial biogenesis during aging is currently unknown, but it seems the internal and external regulatory factors are involved (Lopez-Lluch et al. 2008). In accordance, it has been reported that there is no difference between AMPK and p38MAPK, two key signaling molecules, but levels of PGC-1 $\alpha$ were reduced by $\sim 50 \%$ in skeletal muscle of elderly participants compared to young ones (Joseph et al. 2012). Nonetheless, Lanza et al. (2008) couldn't find any significant difference in levels of PGC- $1 \alpha$ in older men compared with young men. However, both of these studies have reported which levels of the PGC- $1 \alpha$ targeted proteins, nuclear respiratory factor 1 (NRF-1) and mitochondrial transcription factor A (TFAM) did not differ across groups (Joseph et al. 2012, Lanza et al. 2008). Interestingly, data from recent studies suggest a significant decrease in PGC- $1 \alpha$ levels in skeletal muscle of aged animal models (Dillon et al. 2012, Ljubicic et al. 2009). For more details about age-related SM-mito, there are quality review papers which are recommended for consultation (Chistiakov et al. 2014, Gaziev et al. 2014, Johnson et al. 2013) (Fig. 1C).

\section{Age-related SM-mito responses to exercise training}

\section{SM-mito dynamic responses to ET}

Mitochondrial dynamic plays a critical role in vertebrate cells during cell division, differentiation, and development and could also be involved in the mitochondrial response to skeletal muscle challenge (Garnier et al. 2005, Liu et al. 2014). The machinery involved in mitochondrial dynamics requires the participation of several proteins (Yan et al. 2012). In both human and animal model studies, it has been shown that acute and chronic exercise affect markers of mitochondrial content and dynamics in young and adult subjects (Cartoni et al. 2005, Ding et al. 2010, Koltai et al. 2012, Perry et al. 2010, Slivka et al. 2012a, Slivka et al. 2012b). Nevertheless, limited data exist about the impact of the exercise training on SM-mito in healthy age groups. Bori et al. (2012) studied mitochondria response to acute effect of exhausted aerobic exercise on active and sedentary old healthy men. They found that in the old sedentary group mRNA levels of both Mnf1 and Fis1 significantly decreased $(\mathrm{p}<0.05)$ after exercise. In old active group, mRNA levels of Fis1 also decreased $(\mathrm{p}<0.01)$ but there was no change for Mfn1. In contrast to acute aerobic exercise, Konopka et al. (Konopka et al. 2014) reported that twelve weeks aerobic training on a cycle ergometer significantly increased $(p<0.05)$ mitochondrial protein contents of Mfn1, Mfn2 and Fis1 in the in healthy old subjects $(93 \% \pm 44 \%, 36 \% \pm 8 \%$ and $201 \% \pm 98 \%$ respectively). However, there was no change in mRNA levels of Opa1 (Konopka et al. 2014). At variance with humans' studies, endurance training led to a significant decrease in protein levels of Mfn1 in SM-mito of old rats (Bo et al. 2013, Koltai et al. 2012). Nevertheless, twelve weeks treadmill training increased $(\mathrm{p}<0.05)$ Drp1 expression in old rats (Bo et al. 2013). Ziaaldini et al. (2015) also reported that six weeks of treadmill running at the intensity of $60 \%$ of $\mathrm{VO} 2 \mathrm{max}$ eliminated the age-associated loss of muscle cytochrome $\mathrm{C}$ and $\mathrm{COX} 4$ protein content in old rats (Fig. 1D).

\section{SM-mito biogenesis responses to ET}

It is well established that endurance exercise training not only increases physical performance (Yan et al. 2012) but also induces a numbers of adaptations in aged SM-mito including increased aerobic capacity (Holloszy 1967, Holloszy and Coyle 1984), number and size (Palmer 2010, Yan et al. 2012) and consequently mitochondria biogenesis (Joseph et al. 2006, Little et al. 2010) in young and adult of both humans and animals. However, several studies have investigated acute and chronic effects of ET on SM-mito adaptations on old subjects (Huang and Hood 2009, Kang et al. 2013, Li et al. 2011, Menshikova et al. 2006, Palmer 2010, Russell et al. 2014, Toledo and Goodpaster 2013, Yan et al. 2012) and have reported a wide range of structural and functional adaptations in SM-mito such as an increased protein content and volume (Coggan et al. 1992b, Jubrias et al. 2001, Sharman et al. 2001), oxidative, Krebs cycle and electron transport chain enzymes activity (Kang et al. 2013, Li et al. 2011, McArdle et al. 2001, Menshikova et al. 2006). Despite the fact that mitochondria biogenesis requires a coordinated regulation between nuclear and mitochondria encoded gens, the main mechanism involved in SM-mito adaptation in older humans is not well understood yet.

In recent years, PGC- $1 \alpha$ has widely been investigated in cell metabolism (Hood 2009). As mentioned before, PGC- $1 \alpha$ is one of the main regulators of mitochondria adaptations and involves in regulation and expression of gens which are involved in 
mitochondria biogenesis including NRF-1 and NRF-2 and consequently TFAM and mtDNA replication (Broskey et al. 2014). However, data from studies in connection with expression and content levels of PGC- $1 \alpha$ in SM-mito in response to ET, is inconsistent as they show increase (Hood 2009, Kang et al. 2013, Konopka et al. 2014, Yan et al. 2012), decrease (Bori et al. 2012, Koltai et al. 2012, Lanza et al. 2008) and no change (Konopka et al. 2010). For example, Kang et al. (2013), have demonstrated 12 weeks of ET (five days/week, $45 \mathrm{~min} /$ day, $10 \%$ slope and $17.5 \mathrm{~m} / \mathrm{min}$ ) resulted in increase to 2.3 folds of PGC-1 $\alpha$ protein content in aged rat soleus muscle compared with the control group. Whereas, the study by Konopka et al. (2010), revealed that 12 weeks ET on bicycle ergometer led to a reduction of approximately $20 \%(\mathrm{p}<0.05)$ in protein content of PGC-1 $\alpha$ SM-mito in old women (Konopka et al. 2010). Finally, Bori et al. (2012), studied mitochondria protein expression in response to acute exhaustive ET health active and sedentary aged men. Results from vastus lateralis before and after exercise intervention showed there was not difference in mRNA levels of PGC- $1 \alpha$ neither of the two groups (Bori et al. 2012). However, large numbers of studies have reported that PGC- $1 \alpha$ downstream transcription factors, NRF-1 and TFAM, increased following the ET (Broskey et al. 2014, Hood 2009, Kang et al. 2013, Lanza et al. 2008, Russell et al. 2014). Interestingly, some studies which reported significant decreased (Konopka et al. 2010) or unchanged (Bori et al. 2012) level of protein content and mRNA expression of PGC-1- $\alpha$ showed unaltered levels in mRNA of TFAM and decreased level of NRF-1 respectively.

Under normal conditions, control and regulation of PGC-1 $\alpha$ in skeletal muscle in response to ET mainly occurs by activation of CaMK, p38MAPK, AMPK and NAD+ (Gerhart-Hines et al. 2007, Irrcher et al. 2009, Wright et al. 2007a, Zhang et al. 2014). ET induces p38 MAPK phosphorylating and activating transcription factor-2 (ATF-2), allowing the latter to bind to the cAMP-response element-binding protein (CREB) site on the PGC-1 $\alpha$ promoter and induce PGC-1 $\alpha$ gene expression (Russell et al. 2014). In this regard, Kang et al. (2013), have demonstrated 12 weeks ET significantly increased p-p38mapk expression in old rats which was along with elevated levels of CREB phosphorylation and DNA binding. However, among p38 isoforms (i.e. $\alpha, \beta$ and $\gamma$ ), it seems p38\%MAPK plays an important role for normal metabolic adaptation to ET inside skeletal muscle
(Yan et al. 2012). Kang et al. (2013), also reported p-AMPK, containing another upstream enzyme which regulates CREB activity, significantly increased in response to ET (Kang et al. 2013). In another study, it was demonstrated that age related reduction in total p-AMPK reversed following 6 week ET and significantly increased in old rats (Koltai et al. 2012).

It has been shown that Sirtuin family, especially Sirt1, can be involved in SM-mito adaptations to ET (Radak et al. 2013). Mechanical stretch promote Sirt1 transcription by Early growth response protein 1 (Egr1) recruitment to the Sirt1 promoter (Pardo and Boriek 2011). Exercise diminish the ATP/AMP ratio, activate AMPK which leads to an increase in NAD availability by inducing Nicotinamide phosphoribosyltransferase (Nmpt) expression (Pardo and Boriek 2011). The consequent increase in Sirt1 content and/or activity modulates the transcriptional activity of PGC-1 (Pardo and Boriek 2011). It has been well established that Chronic and acute ET increased mRNA expression and protein content of Sirt1 in SM-mito in both old human and animals (Bori et al. 2012, Kang et al. 2013, Koltai et al. 2012, Lanza et al. 2008). Koltai et al. reported Sirt1 activity significantly increased following 6 weeks ET in the cytoplasmic and nuclear extracts of quadriceps muscle in 28 old rats. They also found exercise increased NAMPT level and prevented the age-dependent decrease in NAD+ level in muscles of aged animals suggesting that the age-associated decreases in NAD + and NAMPT levels were reversed with regular exercise, leading to increased specific activity of SIRT1 (Koltai et al. 2010) (Fig. 1D).

\section{Resistance training adaptation}

Resistance training is well known for increasing strange, fat free mass and protein synthesis in difference ages (Tarnopolsky 2009), although a number of studies have documented some SM-mito adaptations to RT such as improved endurance capacity (Ades et al. 1996), increased mitochondria capacity and abundance of translation (Tarnopolsky 2009). Also an increase in mitochondrial volume has been reported following the 12 months $\mathrm{RT}$ in old women $(\%$ of mitochondria = $0.86 \%$ at baseline, $1.19 \%$ at six months and $1.04 \%$ at 12 months, $\mathrm{p}<0.05$ ) (Manfredi et al. 2013). These findings along with other studies that demonstrated RT leads to an increase in mitochondrial ATP production and mitochondrial protein gene expression in healthy old subjects (Melov et al. 2007, Williams et al. 2007), support the hypothesis that RT results in structural and 
functional adaptation in SM-mito network (Hiona et al. 2010, Marzetti et al. 2013, Wu et al. 2009).

It has been proposed that the loss of autophagy with age leads to accumulation of damaged mitochondria, which promote cell death and inflammation, both of which are otherwise limited by autophagy (Green et al. 2011). Recently it has been shown by Luo et al. (2013), that following the 9 weeks RT in old rats, levels of autophagy regulatory proteins, including Beclin 1, Atg5/12, Atg7, and the lysosomal enzyme cathepsin L increased. They also have shown RT reduced cytochrome c level in the cytosol but increased its level in mitochondrial fraction, and inhibited cleaved caspase 3 production and apoptosis. Furthermore, RT upregulated the expression of IGF-1 and its receptors, the expression of total AMPK, phosphorylated AMPK, and FOXO3a (Luo et al. 2013). The exact molecular mechanisms of these adaptations are not well understood yet. However, one possibility mechanism for SM-mito adaption to RT can be by activation of IGF-1/MAPK pathway. It is well established that RT increases levels of IGF-1 in the elderly (Caetano et al. 2008, Cassilhas et al. 2010, Hameed et al. 2004). MAPK pathways regulate diverse processes ranging from proliferation and differentiation to apoptosis (Qi and Elion 2005). The MAPKs consist of growth factor-regulated extracellular signal related kinases 1 and 2 (ERK1/2), and the stress-activated MAPKs, c-jun NH2-terminal kinase (JNK) and p38 MAPK and increased MAPK activity after exercise has been shown to be important for exercise-mediated gene expression, which may contribute to the role of exercise ameliorating the effects of aging in skeletal muscle (Flach and Bennett 2010).

Another possibility, as recent studies have reported, could be the expression of new transcription form of PGC-1 $\alpha$ (PGC-1 $\alpha 4)$, which abundantly expressed in skeletal muscle, increased after RT in human and animals (Millay and Olson 2013, Ruas et al. 2012, Ydfors et al. 2013). However, it is questionable whether biological effects of PGC-1 $1 \alpha 4$ is limited to skeletal muscle hypertrophy (Ruas et al. 2012) or it is also involved in SM-mito adaptation to RT (Ydfors et al. 2013) (Fig. 1D).

\section{Conclusion}

A decline in mitochondrial function including impaired biogenesis and dynamics of mitochondria not only endangers the performance of the cell but also along with other factors such as increased systemic inflammation and reduced growth factors (such as IGF-1) associated with aging (Marzetti and Leeuwenburgh 2006, Roubenoff 2000), leads to the development of programmed cell death and ultimately cell senescence (Chabi et al. 2008, Hiona et al. 2010). Investigations done on healthy elderly, suggest the decrease in gene expression and the content of PGC-1 $\alpha$ is associated with mitochondrial dysfunction in skeletal muscle of elderly subjects (Lopez-Lluch et al. 2008, Wenz et al. 2009). This decline in activity and content of PGC- $1 \alpha$ can be, at least in part, due to age-related disruption in the upstream pathways of AMPK (Salminen and Kaarniranta 2012) and $\mathrm{NAD}^{+} / \mathrm{NADH}$ (Braidy et al. 2011). Exercise has been shown to effectively improve mitochondrial function in the healthy elderly. Although the exact mechanism of this adaptation is not well understood, however, it can be, at least in part, due to an increased activity of AMPK (Bori et al. 2012, Hardman et al. 2012, Li et al. 2012) and $\mathrm{NAD}+\mathrm{NADH}$ ratio due to the increasing energy requirements (Hipkiss 2010, Koltai et al. 2010), as well as increased levels of growth factors (Craig et al. 1989, Vale et al. 2009, Yarasheski et al. 1995, Ziaaldini et al. 2015) followed both endurance and resistance exercise. Finally, despite the beneficial health effects of exercise in the elderly, in order to prescribe the optimal physical activity, future research should answer the following questions:

Which type of training can lead to more favorable effects? How about concurrent training?

In order to achieve the greatest impact, how it should be designed the intensity, duration and frequency of exercise?

Can nutritional and pharmaceutical interventions enhance the effects of physical activity?

\section{Conflict of Interest}

There is no conflict of interest.

\section{References}

ABRESCH RT, CARTER GT, HAN JJ, MCDONALD CM: Exercise in neuromuscular diseases. Phys Med Rehabil Clin N Am 23: 653-673, 2012. 
ADES PA, BALLOR DL, ASHIKAGA T, UTTON JL, NAIR KS: Weight training improves walking endurance in healthy elderly persons. Ann Intern Med 124: 568-572, 1996.

ATAMNA H: Heme, iron, and the mitochondrial decay of ageing. Ageing Res Rev 3: 303-318, 2004.

BO H, JIANG N, JI LL, ZHANG Y: Mitochondrial redox metabolism in aging: Effect of exercise interventions. $J$ Sport Health Sci 2: 67-74, 2013.

BORI Z, ZHAO Z, KOLTAI E, FATOUROS IG, JAMURTAS AZ, DOUROUDOS, II, TERZIS G, CHATZINIKOLAOU A, SOVATZIDIS A, DRAGANIDIS D, BOLDOGH I, RADAK Z: The effects of aging, physical training, and a single bout of exercise on mitochondrial protein expression in human skeletal muscle. Exp Gerontol 47: 417-424, 2012.

BRAIDY N, GUILLEMIN GJ, MANSOUR H, CHAN-LING T, POLJAK A, GRANT R: Age related changes in NAD + metabolism oxidative stress and Sirtl activity in Wistar rats. PLoS One 6: e19194, 2011.

BROSKEY NT, GREGGIO C, BOSS A, BOUTANT M, DWYER A, SCHLUETER L, HANS D, GREMION G, KREIS R, BOESCH C, CANTO C, AMATI F: Skeletal muscle mitochondria in the elderly: effects of physical fitness and exercise training. J Clin Endocrinol Metab 99: 1852-1861, 2014.

CAETANO LF, SANTOS CAS, BASTOS FAC, CASTRO JC, PIRES T, DANTAS EHM: Serum levels of IGF-1 in elderly women engaged in various motor activities. Phys Edu Sport 52: 81-83, 2008.

CARTONI R, LEGER B, HOCK MB, PRAZ M, CRETTENAND A, PICH S, ZILTENER JL, LUTHI F, DERIAZ O, ZORZANO A, GOBELET C, KRALLI A, RUSSELL AP: Mitofusins 1/2 and ERRalpha expression are increased in human skeletal muscle after physical exercise. J Physiol 567: 349-358, 2005.

CASSILHAS RC, ANTUNES HK, TUFIK S, DE MELLO MT: Mood, anxiety, and serum IGF-1 in elderly men given 24 weeks of high resistance exercise. Percept Mot Skills 110: 265-276, 2010.

CHABI B, LJUBICIC V, MENZIES KJ, HUANG JH, SALEEM A, HOOD DA: Mitochondrial function and apoptotic susceptibility in aging skeletal muscle. Aging Cell 7: 2-12, 2008.

CHAN DC: Mitochondria: dynamic organelles in disease, aging, and development. Cell 125: 1241-1252, 2006.

CHEN H, VERMULST M, WANG YE, CHOMYN A, PROLLA TA, MCCAFFERY JM, CHAN DC: Mitochondrial fusion is required for mtDNA stability in skeletal muscle and tolerance of mtDNA mutations. Cell 141: 280-289, 2010.

CHISTIAKOV DA, SOBENIN IA, REVIN VV, OREKHOV AN, BOBRYSHEV YV: Mitochondrial aging and age-related dysfunction of mitochondria. BioMed Res Int 2014: 238463, 2014.

CLAYTON DA: Transcription and replication of mitochondrial DNA. Hum Reprod 15 (Suppl 2): 11-17, 2000.

COBLEY JN, SAKELLARIOU GK, MURRAY S, WALDRON S, GREGSON W, BURNISTON JG, MORTON JP, IWANEJKO LA, CLOSE GL: Lifelong endurance training attenuates age-related genotoxic stress in human skeletal muscle. Longev Healthspan 2: 11, 2013.

COGGAN AR, SPINA RJ, KING DS, ROGERS MA, BROWN M, NEMETH PM, HOLLOSZY JO: Histochemical and enzymatic comparison of the gastrocnemius muscle of young and elderly men and women. J Gerontol 47 : B71-B76, 1992a.

COGGAN AR, SPINA RJ, KING DS, ROGERS MA, BROWN M, NEMETH PM, HOLLOSZY JO: Skeletal muscle adaptations to endurance training in 60- to 70-yr-old men and women. J Appl Physiol (1985) 72: 1780-1786, 1992b.

COOPER JM, MANN VM, SCHAPIRA AH: Analyses of mitochondrial respiratory chain function and mitochondrial DNA deletion in human skeletal muscle: effect of ageing. J Neurol Sci 113: 91-98, 1992.

CRAIG BW, BROWN R, EVERHART J: Effects of progressive resistance training on growth hormone and testosterone levels in young and elderly subjects. Mech Ageing Dev 49: 159-169, 1989.

CUI H, KONG Y, ZHANG H: Oxidative stress, mitochondrial dysfunction, and aging. J Signal Transduct 2012: 646354, 2012.

DAVINELLI S, SAPERE N, VISENTIN M, ZELLA D, SCAPAGNINI G: Enhancement of mitochondrial biogenesis with polyphenols: combined effects of resveratrol and equol in human endothelial cells. Immun Ageing 10: 28, 2013.

DILLON LM, REBELO AP, MORAES CT: The role of PGC-1 coactivators in aging skeletal muscle and heart. IUBMB Life 64: 231-241, 2012. 
DING H, JIANG N, LIU H, LIU X, LIU D, ZHAO F, WEN L, LIU S, JI LL, ZHANG Y: Response of mitochondrial fusion and fission protein gene expression to exercise in rat skeletal muscle. Biochim Biophys Acta 1800: 250-256, 2010.

ESTAQUIER J, VALLETTE F, VAYSSIERE JL, MIGNOTTE B: The mitochondrial pathways of apoptosis. Adv Exp Med Biol 942: 157-183, 2012.

FLACH RJR, BENNETT AM: MAP kinase phosphatase-1-a new player at the nexus between sarcopenia and metabolic disease. Aging (Albany NY) 2: 170-176, 2010.

GARNIER A, FORTIN D, ZOLL J, N'GUESSAN B, METTAUER B, LAMPERT E, VEKSLER V, VENTURACLAPIER R: Coordinated changes in mitochondrial function and biogenesis in healthy and diseased human skeletal muscle. FASEB J 19: 43-52, 2005.

GAZIEV AI, ABDULLAEV S, PODLUTSKY A: Mitochondrial function and mitochondrial DNA maintenance with advancing age. Biogerontology 15: 417-438, 2014.

GERHART-HINES Z, RODGERS JT, BARE O, LERIN C, KIM SH, MOSTOSLAVSKY R, ALT FW, WU Z, PUIGSERVER P: Metabolic control of muscle mitochondrial function and fatty acid oxidation through SIRT1/PGC-1alpha. EMBO J 26: 1913-1923, 2007.

GOFFART S, WIESNER RJ: Regulation and co-ordination of nuclear gene expression during mitochondrial biogenesis. Exp Physiol 88: 33-40, 2003.

GREEN DR, GALLUZZI L, KROEMER G: Mitochondria and the autophagy-inflammation-cell death axis in organismal aging. Science 333: 1109-1112, 2011.

HALL AR, BURKE N, DONGWORTH RK, HAUSENLOY DJ: Mitochondrial fusion and fission proteins: novel therapeutic targets for combating cardiovascular disease. Br J Pharmacol 171: 1890-1906, 2014.

HAMEED M, LANGE KH, ANDERSEN JL, SCHJERLING P, KJAER M, HARRIDGE SD, GOLDSPINK G: The effect of recombinant human growth hormone and resistance training on IGF-I mRNA expression in the muscles of elderly men. J Physiol 555: 231-240, 2004.

HARDMAN SE, HALL DE, MITCHELL AJ, BLACK KM, COMPTON RA, THOMSON DM: The effects of aging and muscle contraction on AMPK activity. FASEB J 26: 2012.

HAWLEY JA: Molecular responses to strength and endurance training: are they incompatible? Appl Physiol Nutr Metab 34: 355-361, 2009.

HEBERT SL, LANZA IR, NAIR KS: Mitochondrial DNA alterations and reduced mitochondrial function in aging. Mech Ageing Dev 131: 451-462, 2010.

HIONA A, SANZ A, KUJOTH GC, PAMPLONA R, SEO AY, HOFER T, SOMEYA S, MIYAKAWA T, NAKAYAMA C, SAMHAN-ARIAS AK, SERVAIS S, BARGER JL, PORTERO-OTIN M, TANOKURA M, PROLLA TA, LEEUWENBURGH C: Mitochondrial DNA mutations induce mitochondrial dysfunction, apoptosis and sarcopenia in skeletal muscle of mitochondrial DNA mutator mice. PLoS One 5: e11468, 2010.

HIPKISS AR: Mitochondrial dysfunction, proteotoxicity, and aging: causes or effects, and the possible impact of NAD+-controlled protein glycation. Adv Clin Chem 50: 123-150, 2010.

HOLLOSZY JO: Biochemical adaptations in muscle. Effects of exercise on mitochondrial oxygen uptake and respiratory enzyme activity in skeletal muscle. J Biol Chem 242: 2278-2282, 1967.

HOLLOSZY JO, COYLE EF: Adaptations of skeletal-muscle to endurance exercise and their metabolic consequences. J Appl Physiol 56: 831-838, 1984.

HOLLOSZY JO, OSCAI LB, DON IJ, MOLÉ PA: Mitochondrial citric acid cycle and related enzymes: adaptive response to exercise. Biochem Biophys Res Commun 40: 1368-1373, 1970.

HOOD DA: Mechanisms of exercise-induced mitochondrial biogenesis in skeletal muscle. Appl Physiol Nutr Metab 34: 465-472, 2009.

HUANG JH, HOOD DA: Age-associated mitochondrial dysfunction in skeletal muscle: contributing factors and suggestions for long-term interventions. IUBMB Life 61: 201-214, 2009.

IQBAL S, HOOD DA: Oxidative stress-induced mitochondrial fragmentation and movement in skeletal muscle myoblasts. Am J Physiol Cell Physiol 306: C1176-C1183, 2014.

IRRCHER I, LJUBICIC V, HOOD DA: Interactions between ROS and AMP kinase activity in the regulation of PGC-1alpha transcription in skeletal muscle cells. Am J Physiol Cell Physiol 296: C116-C123, 2009. 
JAGER S, HANDSCHIN C, ST-PIERRE J, SPIEGELMAN BM: AMP-activated protein kinase (AMPK) action in skeletal muscle via direct phosphorylation of PGC-1alpha. Proc Natl Acad Sci U S A 104: 12017-12022, 2007.

JENKINS NT, MARTIN JS, LAUGHLIN MH, PADILLA J: Exercise-induced signals for vascular endothelial adaptations: Implications for cardiovascular disease. Curr Cardiovasc Risk Rep 6: 331-346, 2012.

JOHNSON ML, ROBINSON MM, NAIR KS: Skeletal muscle aging and the mitochondrion. Trends Endocrinol Metab 24: 247-256, 2013.

JONES JM, DATTA P, SRINIVASULA SM, JI W, GUPTA S, ZHANG Z, DAVIES E, HAJNOCZKY G, SAUNDERS TL, VAN KEUREN ML, FERNANDES-ALNEMRI T, MEISLER MH, ALNEMRI ES: Loss of Omi mitochondrial protease activity causes the neuromuscular disorder of mnd2 mutant mice. Nature 425 : 721-727, 2003.

JORNAYVAZ FR, SHULMAN GI: Regulation of mitochondrial biogenesis. Essays Biochem 47: 69-84, 2010.

JOSEPH AM, ADHIHETTY PJ, BUFORD TW, WOHLGEMUTH SE, LEES HA, NGUYEN LM, ARANDA JM, SANDESARA BD, PAHOR M, MANINI TM, MARZETTI E, LEEUWENBURGH C: The impact of aging on mitochondrial function and biogenesis pathways in skeletal muscle of sedentary high- and low-functioning elderly individuals. Aging Cell 11: 801-809, 2012.

JOSEPH AM, PILEGAARD H, LITVINTSEV A, LEICK L, HOOD DA: Control of gene expression and mitochondrial biogenesis in the muscular adaptation to endurance exercise. Essays Biochem 42: 13-29, 2006.

JUBRIAS SA, ESSELMAN PC, PRICE LB, CRESS ME, CONLEY KE: Large energetic adaptations of elderly muscle to resistance and endurance training. $J$ Appl Physiol 90: 1663-1670, 2001.

KANG C, CHUNG E, DIFFEE G, JI LL: Exercise training attenuates aging-associated mitochondrial dysfunction in rat skeletal muscle: role of PGC-1alpha. Exp Gerontol 48: 1343-1350, 2013.

KOLTAI E, HART N, TAYLOR AW, GOTO S, NGO JK, DAVIES KJ, RADAK Z: Age-associated declines in mitochondrial biogenesis and protein quality control factors are minimized by exercise training. Am J Physiol Regul Integr Comp Physiol 303: R127-R134, 2012.

KOLTAI E, SZABO Z, ATALAY M, BOLDOGH I, NAITO H, GOTO S, NYAKAS C, RADAK Z: Exercise alters SIRT1, SIRT6, NAD and NAMPT levels in skeletal muscle of aged rats. Mech Ageing Dev 131: 21-28, 2010.

KONOPKA AR, DOUGLASS MD, KAMINSKY LA, JEMIOLO B, TRAPPE TA, TRAPPE S, HARBER MP: Molecular adaptations to aerobic exercise training in skeletal muscle of older women. J Gerontol A Biol Sci Med Sci 65: 1201-1207, 2010.

KONOPKA AR, SUER MK, WOLFF CA, HARBER MP: Markers of human skeletal muscle mitochondrial biogenesis and quality control: effects of age and aerobic exercise training. J Gerontol A Biol Sci Med Sci 69: 371-378, 2014.

KUMARAN S, SUBATHRA M, BALU M, PANNEERSELVAM C: Age-associated decreased activities of mitochondrial electron transport chain complexes in heart and skeletal muscle: role of L-carnitine. Chem Biol Interact 148: 11-18, 2004.

LANZA IR, NAIR KS: Muscle mitochondrial changes with aging and exercise. Am J Clin Nutr 89: 467S-471S, 2009.

LANZA IR, SHORT DK, SHORT KR, RAGHAVAKAIMAL S, BASU R, JOYNER MJ, MCCONNELL JP, NAIR KS: Endurance exercise as a countermeasure for aging. Diabetes 57: 2933-2942, 2008.

LEE HC, WEI YH: Mitochondrial biogenesis and mitochondrial DNA maintenance of mammalian cells under oxidative stress. Int J Biochem Cell Biol 37: 822-834, 2005.

LESNEFSKY EJ, MOGHADDAS S, TANDLER B, KERNER J, HOPPEL CL: Mitochondrial dysfunction in cardiac disease: ischemia--reperfusion, aging, and heart failure. J Mol Cell Cardiol 33: 1065-1089, 2001.

LI L, PAN R, LI R, NIEMANN B, AURICH AC, CHEN Y, ROHRBACH S: Mitochondrial biogenesis and peroxisome proliferator-activated receptor-gamma coactivator-1alpha (PGC-1alpha) deacetylation by physical activity: intact adipocytokine signaling is required. Diabetes 60: 157-167, 2011.

LI M, VERDIJK LB, SAKAMOTO K, ELY B, VAN LOON LJ, MUSI N: Reduced AMPK-ACC and mTOR signaling in muscle from older men, and effect of resistance exercise. Mech Ageing Dev 133: 655-664, 2012.

LITTLE JP, SAFDAR A, WILKIN GP, TARNOPOLSKY MA, GIBALA MJ: A practical model of low-volume highintensity interval training induces mitochondrial biogenesis in human skeletal muscle: potential mechanisms. J Physiol 588: 1011-1022, 2010. 
LIU R, JIN P, LIQUNYU, WANG Y, HAN L, SHI T, LI X: Impaired mitochondrial dynamics and bioenergetics in diabetic skeletal muscle. PLoS One 9: e92810, 2014.

LJUBICIC V, JOSEPH AM, ADHIHETTY PJ, HUANG JH, SALEEM A, UGUCCIONI G, HOOD DA: Molecular basis for an attenuated mitochondrial adaptive plasticity in aged skeletal muscle. Aging 1: 818-830, 2009.

LOPEZ-LLUCH G, IRUSTA PM, NAVAS P, DE CABO R: Mitochondrial biogenesis and healthy aging. Exp Gerontol 43: 813-819, 2008.

LOWELL BB, SHULMAN GI: Mitochondrial dysfunction and type 2 diabetes. Science 307: 384-387, 2005.

LUO L, LU AM, WANG Y, HONG A, CHEN Y, HU J, LI X, QIN ZH: Chronic resistance training activates autophagy and reduces apoptosis of muscle cells by modulating IGF-1 and its receptors, Akt/mTOR and Akt/FOXO3a signaling in aged rats. Exp Gerontol 48: 427-436, 2013.

MANFREDI TG, MONTEIRO MA, LAMONT LS, SINGH MF, FOLDVARI M, WHITE S, COSMAS AC, URSO ML: Postmenopausal effects of resistance training on muscle damage and mitochondria. $J$ Strength Cond Res 27: 556-561, 2013.

MARZETTI E, CSISZAR A, DUTTA D, BALAGOPAL G, CALVANI R, LEEUWENBURGH C: Role of mitochondrial dysfunction and altered autophagy in cardiovascular aging and disease: from mechanisms to therapeutics. Am J Physiol Heart Circ Physiol 305: H459-H476, 2013.

MARZETTI E, LEEUWENBURGH C: Skeletal muscle apoptosis, sarcopenia and frailty at old age. Exp Gerontol 41: 1234-1238, 2006.

MCARDLE A, PATTWELL D, VASILAKI A, GRIFFITHS RD, JACKSON MJ: Contractile activity-induced oxidative stress: cellular origin and adaptive responses. Am J Physiol Cell Physiol 280: C621-C627, 2001.

MELOV S, TARNOPOLSKY MA, BECKMAN K, FELKEY K, HUBBARD A: Resistance exercise reverses aging in human skeletal muscle. PLoS One 2: e465, 2007.

MENSHIKOVA EV, RITOV VB, FAIRFULL L, FERRELL RE, KELLEY DE, GOODPASTER BH: Effects of exercise on mitochondrial content and function in aging human skeletal muscle. J Gerontol A Biol Sci Med Sci 61: 534-540, 2006.

MERCER JR: Mitochondrial bioenergetics and therapeutic intervention in cardiovascular disease. Pharmacol Ther 141: 13-20, 2014.

MILLAY DP, OLSON EN: Making muscle or mitochondria by selective splicing of PGC-1alpha. Cell Metab 17: 3-4, 2013.

MURPHY MP: How mitochondria produce reactive oxygen species. Biochem J 417: 1-13, 2009.

NARDIN RA, JOHNS DR: Mitochondrial dysfunction and neuromuscular disease. Muscle Nerve 24: 170-191, 2001.

NEWMAN JC, HE W, VERDIN E: Mitochondrial protein acylation and intermediary metabolism: regulation by sirtuins and implications for metabolic disease. J Biol Chem 287: 42436-42443, 2012.

NISOLI E, CARRUBA MO: Nitric oxide and mitochondrial biogenesis. J Cell Sci 119: 2855-2862, 2006.

NISOLI E, CLEMENTI E, PAOLUCCI C, COZZI V, TONELLO C, SCIORATI C, BRACALE R, VALERIO A, FRANCOLINI M, MONCADA S, CARRUBA MO: Mitochondrial biogenesis in mammals: the role of endogenous nitric oxide. Science 299: 896-899, 2003.

PALMER HS: Exercise training for a time-poor generation: enhanced skeletal muscle mitochondrial biogenesis. J Physiol 588: 1817-1818, 2010.

PARDO PS, BORIEK AM: The physiological roles of Sirt1 in skeletal muscle. Aging 3: 430-437, 2011.

PARISE G, PHILLIPS SM, KACZOR JJ, TARNOPOLSKY MA: Antioxidant enzyme activity is up-regulated after unilateral resistance exercise training in older adults. Free Radic Biol Med 39: 289-295, 2005.

PERRY CG, LALLY J, HOLLOWAY GP, HEIGENHAUSER GJ, BONEN A, SPRIET LL: Repeated transient mRNA bursts precede increases in transcriptional and mitochondrial proteins during training in human skeletal muscle. J Physiol 588: 4795-4810, 2010.

PICARD M, RITCHIE D, THOMAS MM, WRIGHT KJ, HEPPLE RT: Alterations in intrinsic mitochondrial function with aging are fiber type-specific and do not explain differential atrophy between muscles. Aging Cell 10: 1047-1055, 2011.

QI M, ELION EA: MAP kinase pathways. J Cell Sci 118: 3569-3572, 2005. 
RADAK Z, KOLTAI E, TAYLOR AW, HIGUCHI M, KUMAGAI S, OHNO H, GOTO S, BOLDOGH I: Redoxregulating sirtuins in aging, caloric restriction, and exercise. Free Radic Biol Med 58: 87-97, 2013.

REZNICK RM, ZONG H, LI J, MORINO K, MOORE IK, YU HJ, LIU ZX, DONG J, MUSTARD KJ, HAWLEY SA, BEFROY D, PYPAERT M, HARDIE DG, YOUNG LH, SHULMAN GI: Aging-associated reductions in AMP-activated protein kinase activity and mitochondrial biogenesis. Cell Metab 5: 151-156, 2007.

ROUBENOFF R: Sarcopenia and its implications for the elderly. Eur J Clin Nutr 54 (Suppl 3): S40-S47, 2000.

RUAS JL, WHITE JP, RAO RR, KLEINER S, BRANNAN KT, HARRISON BC, GREENE NP, WU J, ESTALL JL, IRVING BA, LANZA IR, RASBACH KA, OKUTSU M, NAIR KS, YAN Z, LEINWAND LA, SPIEGELMAN BM: A PGC-1alpha isoform induced by resistance training regulates skeletal muscle hypertrophy. Cell 151: 1319-1331, 2012.

RUSSELL AP, FOLETTA VC, SNOW RJ, WADLEY GD: Skeletal muscle mitochondria: a major player in exercise, health and disease. Biochim Biophys Acta 1840: 1276-1284, 2014.

SAHIN E, DEPINHO RA: Linking functional decline of telomeres, mitochondria and stem cells during ageing. Nature 464: 520-528, 2010.

SALMINEN A, KAARNIRANTA K: AMP-activated protein kinase (AMPK) controls the aging process via an integrated signaling network. Ageing Res Rev 11: 230-241, 2012.

SAXENA R, DE BAKKER PI, SINGER K, MOOTHA V, BURTT N, HIRSCHHORN JN, GAUDET D, ISOMAA B, DALY MJ, GROOP L, ARDLIE KG, ALTSHULER D: Comprehensive association testing of common mitochondrial DNA variation in metabolic disease. Am J Hum Genet 79: 54-61, 2006.

SCOTT I, LOGAN DC: Mitochondrial Dynamics. In: Plant Mitochondria. KEMPKEN F (ed.), Springer New York, New York, 2011, pp 31-63.

SEO AY, JOSEPH AM, DUTTA D, HWANG JC, ARIS JP, LEEUWENBURGH C: New insights into the role of mitochondria in aging: mitochondrial dynamics and more. J Cell Sci 123: 2533-2542, 2010.

SHABROKH E, KAVANAUGH J, MCMILLAN R, PITTMAN J, HULVER M, FRISARD M: Mitochondrial dysregulation in skeletal muscle from patients diagnosed with Alzheimer's disease and sporadic inclusion body myositis. Open J Mol Integr Physiol 4: 11-19, 2014.

SHARMA J, JOHNSTON MV, HOSSAIN MA: Sex differences in mitochondrial biogenesis determine neuronal death and survival in response to oxygen glucose deprivation and reoxygenation. BMC Neurosci 15: 9, 2014.

SHARMAN MJ, NEWTON RU, TRIPLETT-MCBRIDE T, MCGUIGAN MR, MCBRIDE JM, HAKKINEN A, HAKKINEN K, KRAEMER WJ: Changes in myosin heavy chain composition with heavy resistance training in 60- to 75-year-old men and women. Eur J Appl Physiol 84: 127-132, 2001.

SHEPHERD SO, COCKS M, TIPTON KD, WITARD OC, RANASINGHE AM, BARKER TA, WAGENMAKERS AJ, SHAW CS: Resistance training increases skeletal muscle oxidative capacity and net intramuscular triglyceride breakdown in type I and II fibres of sedentary males. Exp Physiol 99: 894-908, 2014.

SHERMAN IW: Chapter 11 Pyrimidines and the Mitochondrion. Adv Parasitol 67: 95-100, 2008.

SHORT KR, BIGELOW ML, KAHL J, SINGH R, COENEN-SCHIMKE J, RAGHAVAKAIMAL S, NAIR KS: Decline in skeletal muscle mitochondrial function with aging in humans. Proc Natl Acad Sci U S A 102: 5618-5623, 2005.

SLIVKA DR, DUMKE CL, HAILES WS, CUDDY JS, RUBY BC: Substrate use and biochemical response to a 3,211km bicycle tour in trained cyclists. Eur J Appl Physiol 112: 1621-1630, 2012a.

SLIVKA DR, DUMKE CL, TUCKER TJ, CUDDY JS, RUBY B: Human mRNA response to exercise and temperature. Int J Sports Med 33: 94-100, 2012b.

STEFANO GB, KIM C, MANTIONE K, CASARES F, KREAM RM: Targeting mitochondrial biogenesis for promoting health. Med Sci Monit 18: SC1-SC3, 2012.

TARNOPOLSKY MA: Mitochondrial DNA shifting in older adults following resistance exercise training. Appl Physiol Nutr Metab 34: 348-354, 2009.

TERMAN A, KURZ T, NAVRATIL M, ARRIAGA EA, BRUNK UT: Mitochondrial turnover and aging of long-lived postmitotic cells: the mitochondrial-lysosomal axis theory of aging. Antioxid Redox Signal 12: 503-535, 2010. 
TJONNA AE, LEE SJ, ROGNMO O, STOLEN TO, BYE A, HARAM PM, LOENNECHEN JP, AL-SHARE QY, SKOGVOLL E, SLORDAHL SA, KEMI OJ, NAJJAR SM, WISLOFF U: Aerobic interval training versus continuous moderate exercise as a treatment for the metabolic syndrome: a pilot study. Circulation 118: 346-354, 2008.

TOLEDO FG, GOODPASTER BH: The role of weight loss and exercise in correcting skeletal muscle mitochondrial abnormalities in obesity, diabetes and aging. Mol Cell Endocrinol 379: 30-34, 2013.

TRIFUNOVIC A, LARSSON NG: Mitochondrial dysfunction as a cause of ageing. J Intern Med 263: 167-178, 2008.

VALE RG, DE OLIVEIRA RD, PERNAMBUCO CS, DE MENESES YP, NOVAES JDA S, DE ANDRADE ADE F: Effects of muscle strength and aerobic training on basal serum levels of IGF-1 and cortisol in elderly women. Arch Gerontol Geriatr 49: 343-347, 2009.

VERDIN E, HIRSCHEY MD, FINLEY LW, HAIGIS MC: Sirtuin regulation of mitochondria: energy production, apoptosis, and signaling. Trends Biochem Sci 35: 669-675, 2010.

WALLACE DC: Mitochondrial DNA mutations and neuromuscular disease. Trends Genet 5: 9-13, 1989.

WANG C, YOULE RJ: The role of mitochondria in apoptosis. Annu Rev Genet 43: 95-118, 2009.

WANG L, MASCHER H, PSILANDER N, BLOMSTRAND E, SAHLIN K: Resistance exercise enhances the molecular signaling of mitochondrial biogenesis induced by endurance exercise in human skeletal muscle. J Appl Physiol 111: 1335-1344, 2011.

WENZ T, ROSSI SG, ROTUNDO RL, SPIEGELMAN BM, MORAES CT: Increased muscle PGC-1alpha expression protects from sarcopenia and metabolic disease during aging. Proc Natl Acad Sci U S A 106: 20405-20410, 2009.

WESTERMANN B: Bioenergetic role of mitochondrial fusion and fission. Biochim Biophys Acta 1817: 1833-1838, 2012.

WESTERMANN B: Mitochondrial fusion and fission in cell life and death. Nat Rev Mol Cell Biol 11: 872-884, 2010.

WILLIAMS AD, CAREY MF, SELIG S, HAYES A, KRUM H, PATTERSON J, TOIA D, HARE DL: Circuit resistance training in chronic heart failure improves skeletal muscle mitochondrial ATP production rate--a randomized controlled trial. J Card Fail 13: 79-85, 2007.

WILLIS WT, JACKMAN MR: Mitochondrial function during heavy exercise. Med Sci Sports Exerc 26: 1347-1353, 1994.

WRIGHT DC, GEIGER PC, HAN DH, JONES TE, HOLLOSZY JO: Calcium induces increases in peroxisome proliferator-activated receptor gamma coactivator-1alpha and mitochondrial biogenesis by a pathway leading to p38 mitogen-activated protein kinase activation. J Biol Chem 282: 18793-18799, 2007a.

WRIGHT DC, HAN DH, GARCIA-ROVES PM, GEIGER PC, JONES TE, HOLLOSZY JO: Exercise-induced mitochondrial biogenesis begins before the increase in muscle PGC-1alpha expression. $J$ Biol Chem 282: 194-199, $2007 \mathrm{~b}$.

WRIGHT GL, MAROULAKOU IG, ELDRIDGE J, LIBY TL, SRIDHARAN V, TSICHLIS PN, MUISEHELMERICKS RC: VEGF stimulation of mitochondrial biogenesis: requirement of AKT3 kinase. FASEB J 22: 3264-3275, 2008.

WU JJ, QUIJANO C, CHEN E, LIU H, CAO L, FERGUSSON MM, ROVIRA, II, GUTKIND S, DANIELS MP, KOMATSU M, FINKEL T: Mitochondrial dysfunction and oxidative stress mediate the physiological impairment induced by the disruption of autophagy. Aging 1: 425-437, 2009.

YAN Z, LIRA VA, GREENE NP: Exercise training-induced regulation of mitochondrial quality. Exerc Sport Sci Rev 40: 159-164, 2012.

YARASHESKI KE, ZACHWIEJA JJ, CAMPBELL JA, BIER DM: Effect of growth hormone and resistance exercise on muscle growth and strength in older men. Am J Physiol 268: E268-E276, 1995.

YDFORS M, FISCHER H, MASCHER H, BLOMSTRAND E, NORRBOM J, GUSTAFSSON T: The truncated splice variants, NT-PGC-1alpha and PGC-1alpha4, increase with both endurance and resistance exercise in human skeletal muscle. Physiol Rep 1: e00140, 2013.

ZHAN M, BROOKS C, LIU F, SUN L, DONG Z: Mitochondrial dynamics: regulatory mechanisms and emerging role in renal pathophysiology. Kidney Int 83: 568-581, 2013. 
ZHANG Y, UGUCCIONI G, LJUBICIC V, IRRCHER I, IQBAL S, SINGH K, DING S, HOOD DA: Multiple signaling pathways regulate contractile activity-mediated PGC-1alpha gene expression and activity in skeletal muscle cells. Physiol Rep 2: e12008, 2014.

ZIAALDINI MM, KOLTAI E, CSENDE Z, GOTO S, BOLDOGH I, TAYLOR AW, RADAK Z: Exercise training increases anabolic and attenuates catabolic and apoptotic processes in aged skeletal muscle of male rats. Exp Gerontol 67: 9-14, 2015.

ZONG H, REN JM, YOUNG LH, PYPAERT M, MU J, BIRNBAUM MJ, SHULMAN GI: AMP kinase is required for mitochondrial biogenesis in skeletal muscle in response to chronic energy deprivation. Proc Natl Acad Sci U S A 99: 15983-15987, 2002. 